\title{
Paul Claudel, La scarpetta di raso
}

\section{Monia Mezzetti}

\section{(2) OpenEdition}

\section{Journals}

\section{Edizione digitale}

URL: http://journals.openedition.org/studifrancesi/3845

DOI: $10.4000 /$ studifrancesi.3845

ISSN: 2421-5856

\section{Editore}

Rosenberg \& Sellier

\section{Edizione cartacea}

Data di pubblicazione: 1 décembre 2012

Paginazione: 607-608

ISSN: 0039-2944

\section{Notizia bibliografica digitale}

Monia Mezzetti, «Paul Claudel, La scarpetta di raso», Studi Francesi [Online], 168 (LVI | III) | 2012, online dal 30 novembre 2015, consultato il 05 mars 2021. URL: http://journals.openedition.org/studifrancesi/ 3845 ; DOI: https://doi.org/10.4000/studifrancesi.3845

\section{Questo documento è stato generato automaticamente il 5 mars 2021}

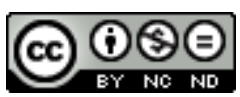

Studi Francesi è distribuita con Licenza Creative Commons Attribuzione - Non commerciale - Non opere derivate 4.0 Internazionale. 


\title{
Paul Claudel, La scarpetta di raso
}

\author{
Monia Mezzetti
}

\section{NOTIZIA}

PAUL CLAUDEL, La scarpetta di raso, traduzione, note e saggio critico a cura di Simonetta VALENTI, Aosta, Le Château, 2011, pp. 535.

1 Simonetta Valenti firma una recente traduzione con testo originale a fronte di Le Soulier de satin (1929), dopo quella a cura di Romeo Lucchese del 1956, ristampata nel 1978 (sempre da Massimo editore, Milano), dal titolo La scarpina di raso. Il testo della pièce è preceduto da una lunga e dettagliata biografia dell'A. e da un non meno particolareggiato sunto della trama (pp.23-27), giustificato dalla ben nota vastità dell'opera, la cui analisi viene condotta nella terza sezione del saggio introduttivo (pp. 28-39) e nelle note, poste al termine di ciascuna delle quattro "giornate". Il significato e le strutture portanti del testo, considerato dalla critica come il capolavoro di Claudel, vengono spiegati mediante la chiave di lettura offerta dall'autore stesso. Accanto al «filo rosso» (p.32) della vicenda passionale che lega i due protagonisti, si distinguono un «filo giallo» (p. 32), rapportabile al tema della cupidigia e della sete di potere, già presente in Tête d'or (1890) e un «filo blu» (p.33), rappresentato dall'intervento costante di personaggi dell'universo spirituale nel ruolo di latori della Provvidenza, ossia i Santi e l'Angelo Custode - quest'ultimo già presente in altre pièces di Claudel, come pure nel teatro simbolista dove tale tipologia di personaggio viene ripresa e in parte rivisitata, ma che qui assume un'importanza sostanziale in quanto egli è l'interlocutore della protagonista nel dialogo, colui che la porterà a maturare l'inopinata decisione di rinunciare all'amore per Rodrigue, cosa da cui discenderà un'altrettanto imprevedibile serie di eventi. A queste chiavi di lettura la Curatrice ne aggiunge una quarta, ovvero il «filo verde» (p.35) corrispondente alla prolungata riflessione sull'arte e che, a suo giudizio, chiarisce le ragioni della predilezione di Claudel per Le Soulier de satin, reputato come il proprio dramma testamentario: la bellezza generata dall'arte, lungi dall'essere fine a se stessa, si configurerebbe come uno sprone per la ricerca di nuovi esemplari di essa, concepita aprioristicamente come 
«frammento di Dio» (p. 35); una prospettiva, questa, da cui la corporeità non è esclusa, in quanto condizione imprescindibile dell'umanità e che, come tale, contribuirebbe a esprimere "l'elemento spirituale", facendo dell'arte stessa una dimensione per definizione "cattolica", nel senso etimologico del termine. L'analisi della Curatrice non si ferma a questi punti irrinunciabili, data l'esegesi condotta dallo stesso Claudel, ma indaga il debito contratto dall'opera con il genere tragico del Classicismo francese (cui scopertamente rinvia il nome del protagonista, doppio rovesciato dell'eroe corneliano), ma anche con il teatro elisabettiano, e in particolare con la produzione di Shakespeare (da Claudel letta in lingua originale), da cui vengono mutuate tanto l'ambientazione storica (il Cinquecento) quanto l'alternanza tra scene liriche e scene comiche. Vengono altresì rilevati il contatto e talora la presa di distanza da tradizioni teatrali diversissime tra loro, come quella di Eschilo, del Secolo d'Oro (modello alla base della sostituzione di atti e scene con le "giornate"), la tradizione drammaturgica giapponese (conosciuta ai tempi della permanenza di Claudel in Giappone quale diplomatico), il cosiddetto "teatro totale" di Wagner e infine il paradigma faustiano. Completa il volume una bibliografia selettiva (pp. 533-535). 